\title{
Consensus PCR and Microarray for Diagnosis of the Genus Staphylococcus, Species, and Methicillin Resistance
}

\author{
S. Hamels, J.-L. Gala ${ }^{1}$, S. Du- \\ four, P. Vannuffel ${ }^{1}$, N. Zam- \\ matteo, and J. Remacle \\ Facultés Universitaires Notre- \\ Dame de la Paix, Namur, and \\ ${ }^{1}$ St. Luc University Hospital and \\ Queen Astrid Military Hospital, \\ Brussels, Belgium
}

\section{ABSTRACT}

We propose the use of DNA microarray for the discrimination of homologous products after a single PCR amplification with consensus primers. The method was applied to Staphylococcus identification. The fem A nucleotide sequences, which are phylogenetically conserved among the staphylococci, were first amplified using a consensus primer pair together with the mecA sequence, a molecular marker for methicillin resistance. Products were then identified on a glass array.

The microarray contained five selective DNA capture probes for the simultaneous and differential identification of the five most clinically relevant staphylococcal species (S. aureus, S. epidermidis, S. haemolyticus, S. hominis, and S. saprophyticus), while a consensus capture probe could detect all femAsequences, allowing the identification of the genus Staphylococcus. The mecAsequence hybridized to a specific capture probe. The identification was univocal because only a single capture probe had to be present for each sequence to be identified. The hybridization and identification processes were completed in less than $2 \mathrm{~h}$. Current results demonstrate that low-density microarrays are powerful multigenotypic post-PCR analyzers and could compete with conventional bacteria identification.

\section{INTRODUCTION}

DNA analysis has gained major diagnostic and therapeutic applications, leading to improved clinical diagnosis, treatment monitoring, and prognosis of diseases. This is mostly due to the major biotechnological developments over the past two decades. PCR, alone or in combination with sequence analysis and hybridization, has been the most commonly used and efficient analysis tool. With the greater availability of genomic information, the selective amplification and identification of multiple nucleotide sequences in a single assay have become critical issues. Multiparametric assays can be performed by multiplex PCR (2). However, multiplex PCR requires the use of as many primers as the number of targets that must be amplified in the reaction. The presence of several primers hampers the amplification efficacy and increases the complexity, time, and cost of the assay $(4,15)$. In addition to the amplification step, the detection of products is another pitfall of the multiparametric PCR process because the products must be different sizes using agarose gel, and real-time PCR is limited by the number of fluorochromes. DNA microarrays allow the simultaneous detection of multiple nucleotide sequences in a simple, miniaturized format assay and, in this way, could be considered for the detection of products $(6,7,10)$.

Here, we demonstrate that the technology of low-density microarrays can be linked with a consensus PCR for the amplification and detection of homologous sequences. Indeed, microorganisms of the same family or genus con- tain phylogenetically conserved genes that encode for the same protein. The sequences of the genes belonging to the same family are often highly homologous. Because of their homology, a consensus single pair of primers can be designed for their common amplification. The products would then be discriminated on the microarray.

The selected application was the identification of the staphylococcal bacteria and their methicillin resistance. This was chosen because of the increasing burden of nosocomial infections in hospitals. The assay combined the PCR amplification of the femA sequences, a highly conserved Staphylococci gene (14) encoding for a precursor of the peptidoglycan $(5,9,12)$, together with their analysis on a DNA microarray bearing capture probes, which were either specific for each species or being designed for genus identification.

We focused the species identification on S. aureus and four coagulasenegative Staphylococci (CoNS) strains (S. epidermidis, S. haemolyticus, S. hominis, and S. Saprophyticus), which, when taken together, represent the main cause of nosocomial infections and more than $95 \%$ of all the Staphylococci strains (8). The identification of the $m e c A$ gene, a universal molecular marker for methicillin resistance (11, 13 ), was added to the assay.

\section{MATERIALS AND METHODS}

\section{Bacterial Strains}

Table 1 shows the 23 ATCC-type culture Staphylococci reference strains used in this study. They were provided by the 
Deutsche Sammlung von Mikroorganismen und Zellkulturen GmbH (DSMZ, Braunschweig, Germany).

\section{Nucleotide Sequence Accession Numbers}

The following nucleotide femA sequences have assigned GenBank ${ }^{\circledR}$ accession nos. (AF144661, AF099964, AF145333, U23714, AF145332, U23713, Y12874, AF144662, AF 099963, Y12875, AF099967, AF099966, U66880, AF144663, and AF099965), and correspond respectively to $S$. aureus subsp. anaerobius, $S$. capitis, $S$. cohnii subsp. urealyticum, $S$. epidermidis, $S$. gallinarum S. haemolyticus, S. hominis, S. intermedius, S. lugdunensis, $S$. saprophyticus, S. schleiferi, S. sciuri, $S$. simulans, S. warneri, and S. xylosus. The femA sequence of $S$. caseolyticus is not published.

\section{Cloning of femA From 16 Staphylococcus Species and of the mecA Sequence}

The femA genes from the 16 Staphylococcus-ATCC species were cloned in the TOPO ${ }^{\circledR}$-XL-PCR vector, according to the manufacturer's instructions (Invitrogen, Carlsbad, CA, USA) and assessed by sequencing analysis (16). The mecA gene was cloned in the TOPO-XL-PCR vector. The bacterial strain used for the transformation was E. coli XL1-Blue. The extraction of plasmid DNA was performed with the Nucleobond ${ }^{\circledR}$ AX100 kit (MachereyNagel GmbH, Düren, Germany). Bacterial strain cultures and DNA purifications were performed as previously described (17).

\section{Co-Amplification of femA and mecA Target DNA by PCR}

The co-amplification of the femA and $m e c A$ genetic marker sequences was performed in a final volume of $50 \mu \mathrm{L}$ containing: $2.5 \mathrm{mM} \mathrm{MgCl}_{2}, 75 \mathrm{mM}$ Tris-HCl, pH 9.0, $50 \mathrm{mM} \mathrm{KCl,} 20 \mathrm{mM}$ $\left(\mathrm{NH}_{4}\right)_{2} \mathrm{SO}_{4}, \quad 0.5 \mu \mathrm{M}$ degenerated primers APcons3-1 (5'-TAAYAAARTCACCAACATAYTC-3') and APcons32 (5'-TYMGNTCATTTATGGAAGATAC-3') (where $\mathrm{Y}$ is $\mathrm{C}$ or $\mathrm{T}, \mathrm{R}$ is $\mathrm{A}$ or $\mathrm{G}$, $\mathrm{M}$ is $\mathrm{A}$ or $\mathrm{C}$, and $\mathrm{N}$ is $\mathrm{A}, \mathrm{G}, \mathrm{C}$, or $\mathrm{T}), 0.1$

Table 1. Comparative ATCC Culture Strains Identification by Conventional Microbiological Methods and DNA Microarrays

\begin{tabular}{|c|c|c|}
\hline ATCC no. & $\begin{array}{l}\text { Microbiological Identification } \\
\text { Bacteria species }\end{array}$ & $\begin{array}{l}\text { Microarray Identification } \\
\text { Bacteria or genusor Species }\end{array}$ \\
\hline 35884 & S. aureus spp anaerobius & S. aureus \\
\hline 27840 & S. capitis spp capitis & Staphylococcus \\
\hline 49326 & S. capitis spp ureolyticus & Staphylococcus \\
\hline 13548 & S. caseolyticus & Staphylococcus \\
\hline 49330 & S. cohnii spp urealyticum & Staphylococcus \\
\hline 14990 & S. epidermidis & S. epidermidis \\
\hline C3572 & S. gallinarum & Staphylococcus \\
\hline 29970 & S. haemolyticus & S. haemolyticus \\
\hline 27844 & S. hominis & S. hominis \\
\hline 29663 & S. intermedius & Staphylococcus \\
\hline 43809 & S. Iugdunensis & Staphylococcus \\
\hline 15305 & S. saprophyticus & S. saprophyticus \\
\hline 43308 & S. schleiferi spp schleiferi & Staphylococcus \\
\hline 29062 & S. sciuri & Staphylococcus \\
\hline 27848 & S. simulans & Staphylococcus \\
\hline 27836 & S. warneri & Staphylococcus \\
\hline 35663 & S. xylosus & Staphylococcus \\
\hline 43300 & S. aureus & S. aureus \\
\hline 35038 & Enterococcus gallinarum & no identification \\
\hline C4239 & Enterococcus flavenscens & no identification \\
\hline 35037 & Streptococcus oralis & no identification \\
\hline 33400 & Streptococcus pneumoniae & no identification \\
\hline 12344 & Streptococcus pyogenes & no identification \\
\hline Negative C & trol & no identification \\
\hline \multicolumn{3}{|c|}{ A methicillin resistance identification was observed for the ATCC } \\
\hline Staphyloc & strain no. 43300 , which was the 0 & only resistant strain. \\
\hline
\end{tabular}

$\mu \mathrm{M}$ of the primers APmec01 (5'-TCTG GAACTTGTTGAGCAGAG-3') and APmec02 (5'-GGCTATCGTGTCACA ATCGTT-3') (all primers were synthesized by Eurogentec, Seraing, Belgium), $200 \mu \mathrm{M}$ dATP, $200 \mu \mathrm{M}$ dCTP, $200 \mu \mathrm{M}$ dGTP, $150 \mu \mathrm{M}$ dTTP, $50 \mu \mathrm{M}$ biotin-16dUTP (all dNTPs from Roche Molecular Biochemicals, Mannheim, Germany), 0.5 U uracil-DNA-glycosylase (Roche Molecular Biochemicals), 1.25 U Taq DNA polymerase (Biotools, Madrid, Spain), $10 \mu \mathrm{L}$ DNA template. For the specificity tests, the plasmid DNA template quantity tested was $1 \mathrm{ng}$ target sequence/tube. The reagents were first incubated at $94^{\circ} \mathrm{C}$ for $5 \mathrm{~min}$ and then cycled 40 times in a model 9600 thermal cycler (Applied Biosystems, Foster City, CA, USA) at $94^{\circ} \mathrm{C}$ for $30 \mathrm{~s}$, $49^{\circ} \mathrm{C}$ for $45 \mathrm{~s}$, and $72^{\circ} \mathrm{C}$ for $30 \mathrm{~s}$. We performed a final extension step of 10 min at $72^{\circ} \mathrm{C}$. The PCR products were directly used or stored at $-20^{\circ} \mathrm{C}$. The products were checked by loading $5 \mu \mathrm{L}$ product on a $2 \%$ (wt/vol) agarose gel. Electrophoresis was performed in $0.1 \mathrm{M}$ Tris-HCl, $\mathrm{pH} 8.6,80 \mathrm{mM}$ boric acid, and $1 \mathrm{mM}$ EDTA buffer containing $0.5 \mu \mathrm{g}$ ethidium bromide/mL. DNA fragments were visualized on a UV transilluminator at $300 \mathrm{~nm}$. 


\section{Low-Density Microarray Design}

The low-density microarray, StaphyChips ${ }^{\circledR}$, was developed in collaboration with Advanced Array Technology (AAT) (Namur, Belgium) for the diagnosis of Staphylococci. The array is presented as a glass slide with the different capture nucleotide sequences covalently attached by an amino group located at the $5^{\prime}$ end onto an aldehyde functionalized slide (18). The spots had $0.4-\mathrm{mm}$ diameters. The array contained 10 detection capture probes present in quadruplicate: five Staphylococcal species, one for the genus Staphylococcus and one for the mecA and several controls. The positive hybridization control capture probe is related to products added to the hybridization solutions. The negative hybridization control is a nonspecific capture probe. The fixation controls are biotinylated capture probes that are spotted either at a high concentration or different concentrations. These four concentrations have been chosen to span between a high- and a low-labeled spot. It provides a good control of the detection efficiency.

The capture probe composition was specifically designed by the manufacturer, with the consensus one complementary to the femA products of $S$. hominis, while the species-specific capture probes, small capture probes of 27 bases, targeted the position 754-780 of each species-specific femA gene. The mecA capture probe was complementary to its target sequence.

\section{Hybridization and Colorimetric Detection}

The procedure for detecting the PCR products was carried out according to the manufacturer's instructions (AAT): $5 \mu \mathrm{L} \mathrm{PCR}$ product and $5 \mu \mathrm{L}$ of the positive control provided in the kit were denatured with $10 \mu \mathrm{L}$ fresh $0.175 \mathrm{~N}$ $\mathrm{NaOH}$ for $5 \mathrm{~min}$ at room temperature. This solution was then mixed with 35 $\mu \mathrm{L}$ hybridization solution and loaded on the array framed by a hybridization chamber (Biozym, Landgraaf, The Netherlands). The chamber was sealed with a plastic coverslip, and hybridization was carried out for $30 \mathrm{~min}$ at $53^{\circ} \mathrm{C}$. Slides were washed four times for $1 \mathrm{~min}$ with washing buffer. The glass samples were then incubated for $45 \mathrm{~min}$ at room temperature with streptavidin labeled with nanoparticles that were diluted 1000 times in blocking buffer. After five washes, the slides were incubated three times for 10 min with revelation mixture and then rinsed with water, dried, and scanned using a Workstation ${ }^{\circledR}$ colorimetric microarray reader with quantification software (AAT).

The intensity of each spot was estimated by averaging the value of all pixels inside its boundaries. The value of the averaged background around the spot was subtracted from the spot values. Because the array was designed to have four replicates for each DNA probe, the value for a given probe was the average of the four replicates, more or less two SD. The last line of a spot was composed of a concentration curve of fixation control and was not treated as mentioned for the replicates. The cut-off value was set up at the intensity equal to five. This cut-off value was taken as the highest value obtained in all experiments for negative spots. The signals greater than this value were considered positive, and those under it were considered negative.

\section{RESULTS}

\section{Consensus Amplification of the femA Nucleotide Sequences Together with $\mathrm{mecA}$}

Figure 1 presents the principle of low-density microarrays for the diagnosis of staphylococcal strains. The method combined the amplification of the femA target sequences using consensus primers, followed by their discrimination by hybridization on specific capture probes present on the array. A second

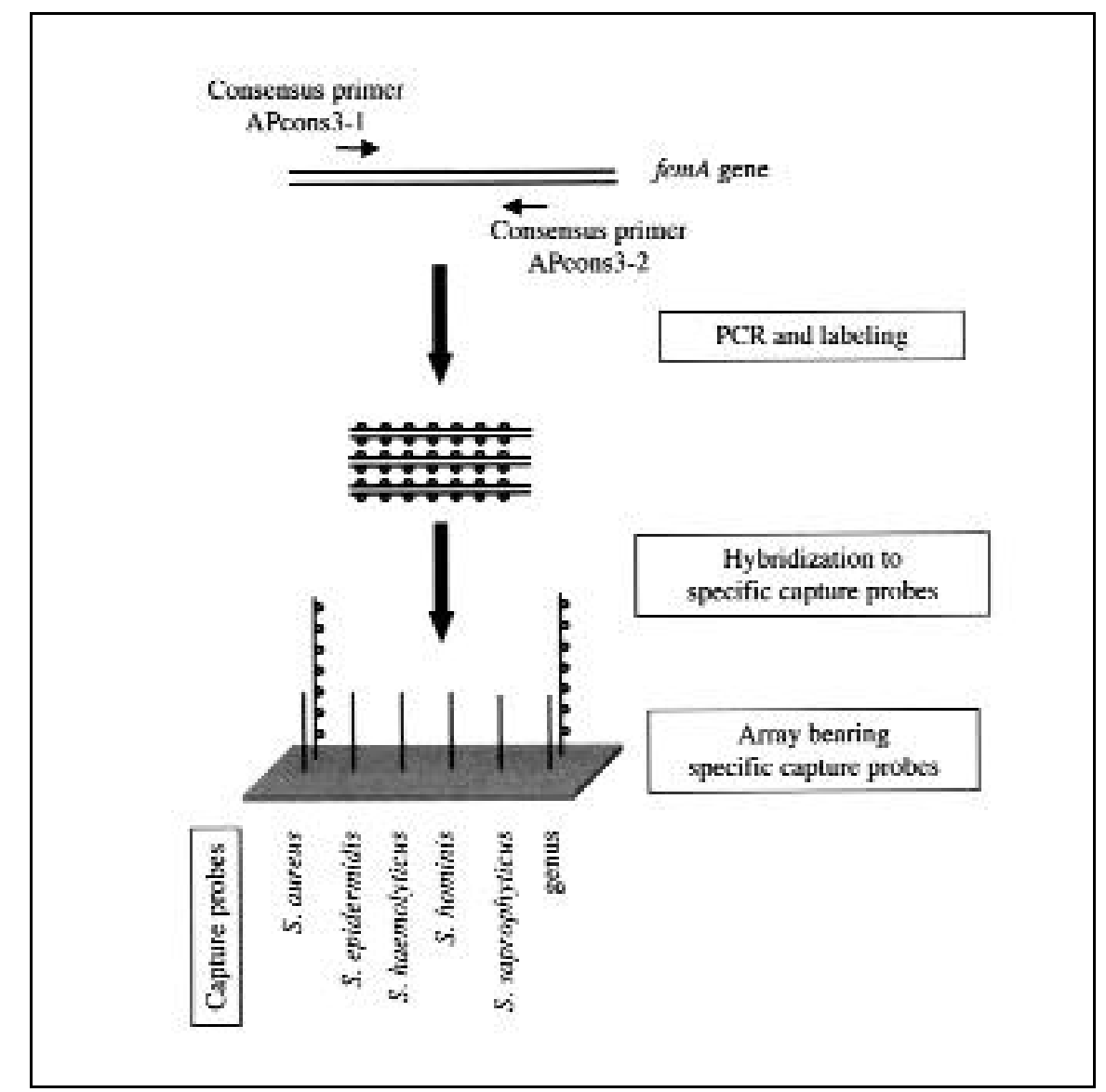

Figure 1. Principle of the two steps differential diagnosis of Staphylococcus. All femA sequences are PCR amplified using consensus primers, and the labeled products are discriminated on the DNA microarray by hybridization to capture probes specific for a given staphylococcal species or of the genus Staphylococcus. 


\section{Molecular Diagnostic Techniques}

primer pair for mecA, testing antibiotic resistance, was added in the reaction.

The femA gene has been sequenced in 16 different Staphylococcus, and their sequence identity ranged from $66 \%$ to $85 \%$. We took advantage of this homology to design partly degenerated consensus primers within two conserved regions of the femA gene. The predicted length of the femA PCR product was 587 bp. For the mecA gene, a specific primer pair with a melting temperature close to that of the femA primers was chosen to avoid a constraint in the duplex PCR. The predicted length of the mecA product was $305 \mathrm{bp}$.

The PCR amplification of femA on the five species of interest and the $m e c A$ gene were first optimized separately and then adjusted to obtain similar efficiency when co-amplified in the duplex PCR. The optimized conditions are provided in the experimental protocol. After the optimization, the amplification of the femA marker was validated on the following 16 Staphylococcal species: S. aureus, S. capitis, S. caseolyticus, S. cohnii, S. epidermidis, $S$. gallinarum, $S$. haemolyticus, $S$. hominis, S. intermedius, S. lugdunensis, $S$. saprophyticus, S. schleiferi, S. sciuri, S. simulans, S. warneri, and S. xylosus. In all samples, the same plasmid carrying the mecA gene was mixed with each of the 16 constructs carrying the speciesspecific femA sequence. Indeed, both products were simultaneously amplified in the 16 staphylococcal species as observed in agarose gel electrophoresis (data not shown). A weaker femA band was obtained for $S$. caseolyticus, which shows two and three mismatches within their femA segments, matching the primers and for S. lugdunensis, which shows five and two mismatches with the primers. The amplification of the 16 femA sequences with the same primers validated their use as consensus primers for the genus Staphylococcus.

\section{Specificity of the Assay}

Different parameters of the hybridization conditions, such as temperature, salt composition, denaturation mode, and incubation time, were optimized for both the detection specificity and sensitivity. The optimized conditions are given in the experimental protocols.

The specificity of the array was assessed by the hybridization of the PCR products from the 16 species-specific femA plasmids mixed with the plasmid carrying the mecA gene. Figure 2 presents an example of a microarray, resulting from the hybridization of femA sequence from $S$. aureus, $S$. epidermidis, S. haemolyticus, S. hominis, S. saprophyticus, and the mecA gene. The fixation and hybridization controls were correctly detected throughout the quadruplicates on the five slides. Each
femA target sequence hybridized to its corresponding specific capture probe. There were no cross-hybridizations. The experiments were repeated five times and produced the same results. The absence of cross-hybridization of the capture probes specific of the five Staphylococci species was also observed with the femA of the other 11 Staphylococci species (Figure 3A). All of the negative PCR controls were clear. The specificity of the hybridization was made possible because of high variability within a portion of the $f e m A$ genes (positions 754-780), which was targeted by the species-specific capture probes. The identity expressed as the minimum and maximum number of mismatches between each of the capture probes and the five other femA sequences were as follows: $S$. aureus (8-16), S. epidermidis (3-17), S. haemolyticus (8-16), S. hominis (9-15), and $S$. saprophyticus (6-14). In all cases, a minimum of three mismatches was present, which explains the perfect discrimination observed.

In contrast to the specificity given by the capture probes for the five species, all $16 \mathrm{femA}$ products hybridized to the genus capture probe (Figure 3B). The signal intensities for the 16 sequences were well above the cut-off value, but with variations in the absolute values. This consensus capture probe was complementary to the S. ho-

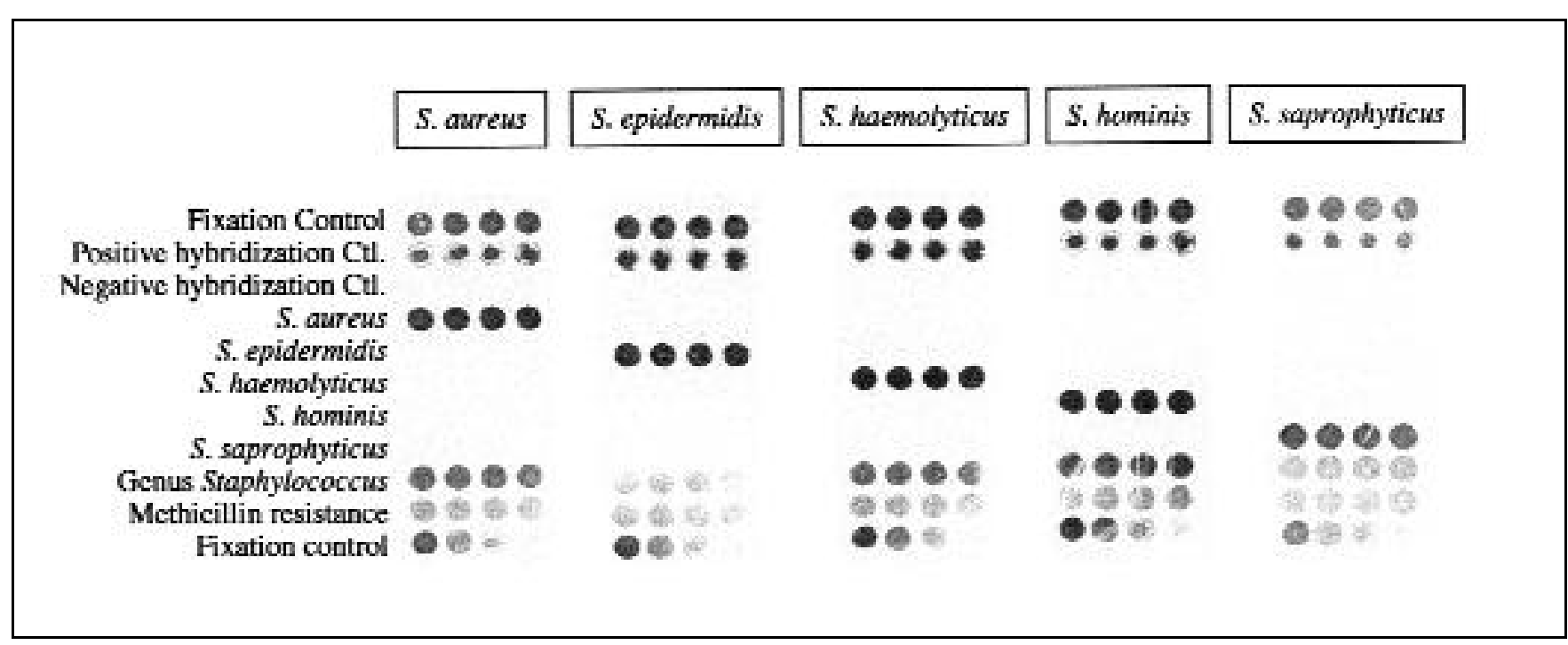

Figure 2. Specificity of the Staphylococcus species determination. The colorimetric detection of biotinylated products after hybridization with $f e m A$ and $m e c A$ duplex PCR products. The femA products from the following Staphylococcus: S. aureus, S. epidermidis, S. haemolyticus, S. hominis, and S. saprophyticus were hybridized to the array. The pictures are digitalized images obtained using a colorimetric microarray reader. 
minis femA sequence. The sequence homology of all the femA sequences with this capture probe was higher than $76 \%$, the lowest one being the femA from $S$. caseolyticus. The variations of the absolute values are probably the result of differences in the PCR amplification and hybridization efficiencies.

The detections of the mecA sequence in the same 16 samples were positive and ranged in absolute value between 93 and 22 gray intensity for the 16 Staphylococci species, with an average value of 62 and a CV of $25 \%$. In this case, the target sequences are identical and perfectly matched with the capture probe. Because the mecA is identical in all samples and the same PCR product volume was hybridized on the arrays, these variations are probably due to the competition in the duplex PCR with the femA amplifications.

The assay specificity was further investigated using 18 ATCC-type culture strains of CoNS and five non-staphylococcal strains. The extracted DNA was PCR amplified, and the products were hybridized to the StaphyChips. The molecular identifications were compared to conventional microbiological assays (Table 1). For the products from the 18 Staphylococcus-ATCC strains, we correctly identified the genus Staphylococcus, the methicillin resistance, and the five specific, targeted staphylococcal species. No cross-species identifications were observed, and all the negative PCR controls were clear.

\section{Sensitivity of the Assay on S. aureus femA and mecA Plasmid DNA}

The detection limit of the assay was assessed using increasing copy num bers of $S$. aureus femA and mecA plasmid DNA, ranging from 10 to $10^{8}$. After PCR amplification and microarray analysis, a detection limit of $10^{4}$ copies was obtained for the signal corresponding to the genus Staphylococcus and $10^{3}$ copies for the $S$. aureus signal (Figure 4). For the mecA, the lowest significant signal was obtained for 10 copies. These detection limits were obtained in two distinct experiments, even if the present experiment did not show a clear linearity between the signals and the dilution in the 10-1000 copies range. The PCR negative controls were clear.

\section{DISCUSSION}

The discovery of new genes and the increasing number of sequences available in public databases lead to the need for multiparametric molecular analytic tools. Microarrays are good candidates, given the miniaturization and the large number of capture probes that can be present on a small surface. Alternatively, PCR is the method of choice for the amplification of DNA sequences. To combine both methods for the analysis of a large number of sequences, it is useful to amplify the sequences with one or a small number of consensus primers. This is only possible if the target sequences are homologous. The most conserved parts of the sequence can then serve as the consensus primers to amplify all the sequences, while the most variable parts provide the specificity of the hybridization to the array.

In this paper, we applied this concept to the detection of femA DNA sequences that are molecular markers for the staphylococcal species (14). Using consensus primers, we obtained the amplification of all 16 staphylococcal species, with differences in the amplification efficiencies. Additional primers specific for the methicillin-resistant determinant $(11,13)$, mecA sequence, were added so that both molecular markers were amplified in a single duplex PCR. The microarrays analyses gave the expected responses and allowed the correct

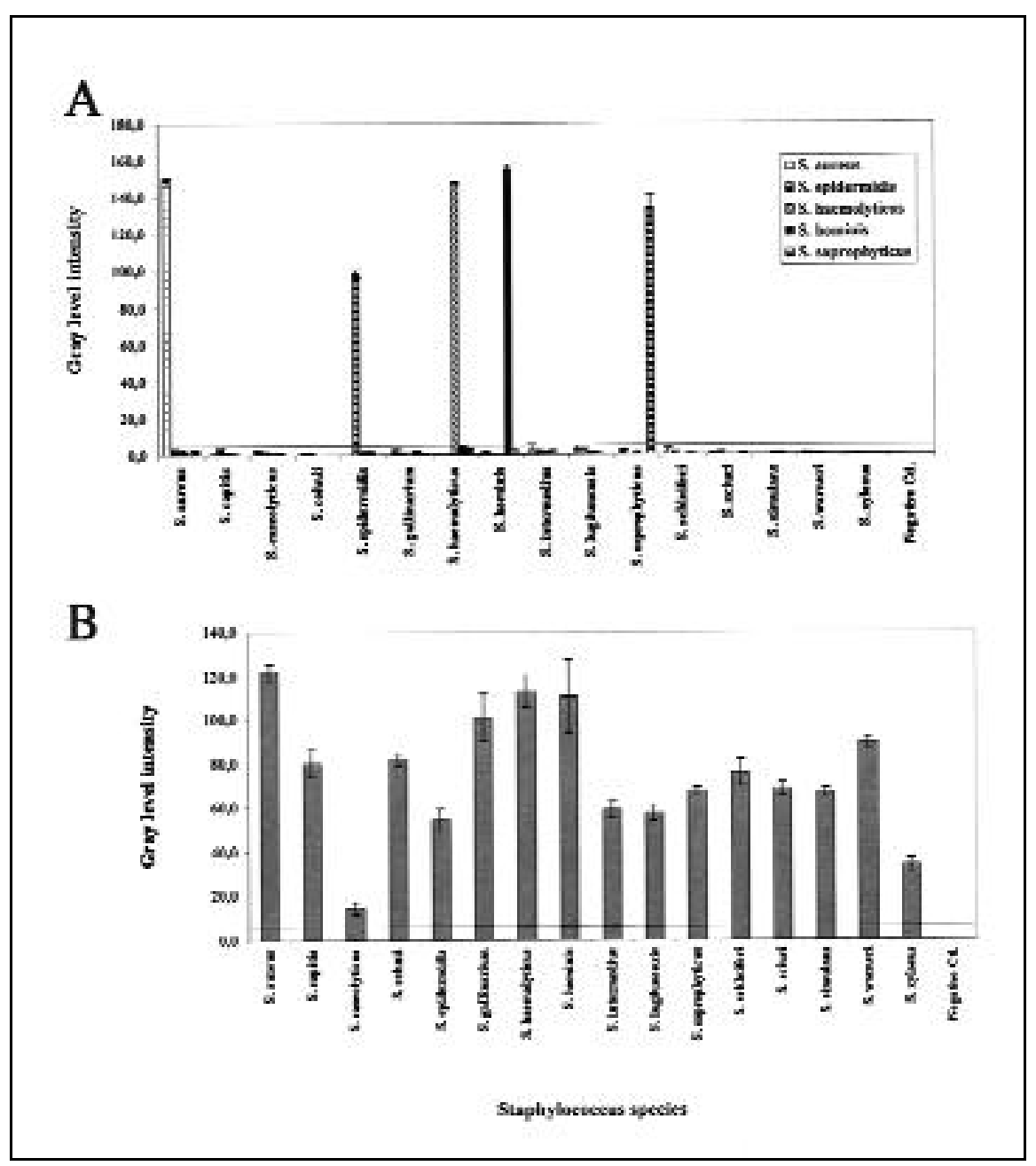

Figure 3. Quantification of the microarrays for the fem Asequences from 16 Staphylococcus species. (A) The fixation of the $16 \mathrm{femA}$ products to the capture probes specific for the five staphylococcal species. (B) The fixation of the 16 femA products to the genus Staphylococcus consensus capture probe. Results are expressed as the mean intensity of quadruplicates with about two SD. The cut-off value (straight line) was fixed to a gray intensity level of five. 


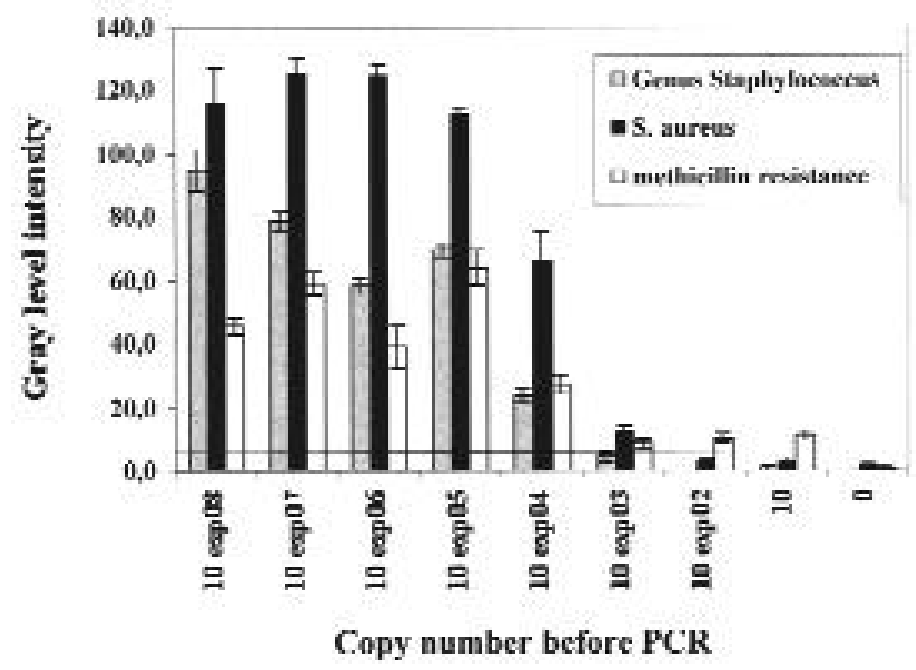

Figure 4. Sensitivity of the Staphylococcus detection on the microarray. Quantification of the microarrays for the Staphylococcus genus, S. aureus species, and mecA capture probe sequences from the hybridization of PCR products, resulting from a PCR performed on increasing copy numbers of femA and $m e c A$ plasmids. Results were expressed as the mean intensity of quadruplicates with about two SD. The cut-off value (straight line) was fixed to a gray level intensity of five. identification of the five most representative staphylococcal species, with no cross-reaction among the species. The use of a single capture probe for each specific identification allows the straightforward interpretation of the results. The presence of the 11 other staphylococcal species that are not of clinical relevance was obtained by a positive signal on a single staphylococcal consensus capture probe (Figure 3B). These results clearly demonstrated that long homologous sequences can be targeted to consensus capture probes, while discrimination between the homologous sequences was possible on a small protion sequence, as exemplified on the species-specific capture probes. However, from a quantitative point of view, the amplification and detection on microarrays did not lead to the same signal for the 16 sequences. The variations in intensity resulted not only from the differences in the PCR efficiency caused by 
the use of consensus primers but also of the hybridization yield, and this for a capture probe either long as consensus for the genus identification or short as for the species identification. Such variations are intrinsic to the methodology.

The detection limit of the assay was lower than $10^{4}$ copies of plasmid DNA. To identify false-negative PCR results caused by enzymatic inhibition, further exogenous internal controls could be added to the sample before the reaction. In the optimized protocol, the array hybridization, washing, and detection time were reduced to $2 \mathrm{~h}$. Overall, the time required to get a final result including extraction and DNA amplification is $6 \mathrm{~h}$, while conventional genus, species, and resistance identification takes 1-3 days. This gain of time largely compensates for the higher price of the molecular assay.

The colorimetric detection method based on silver staining coloration was specific, inexpensive, and highly sensitive, which makes it suitable for routine use (1). A similar approach for the identification of Staphylococcus has been recently proposed based on the amplification of the 23S ribosomal DNA. However, in most cases, several capture probes were necessary for the identification of one species because of the similarity between the sequences (3).

In conclusion, we show one methodology of using low-density microarrays as a molecular diagnostic tool. The StaphyChips were developed for the genus Staphylococcus, but the same methodology can be applied for each bacterial genus, thus opening the door to molecular bacterial diagnosis. The limited number of analytical data and the univocal response of such low-density arrays provide rapid answers to some clinically relevant issues, thus contributing to better infected patient isolation and therapeutic policy. The discriminating power of the assay can be extended by adding capture probes to the panel, without significantly increasing the complexity or cost of the assay. Further automation of the three parts of the assay (i.e., DNA extraction, PCR amplification, and hybridization detection) is expected to further speed up the analytical procedure. This will make this approach a possible candidate technology aimed to convert the actual taxonomic analysis based on biochemical characters into the rapid molecular identification of bacterial species and genus.

\section{ACKNOWLEDGMENTS}

This work was financially supported by the Région Wallonne, Belgium, and grant no. G99/01 from JSM-R\&D-T2, the Joint Staff section of the Belgian Army, supporting research and development.

\section{REFERENCES}

1.Alexandre, I., S. Hamels, S. Dufour, J. Collet, N. Zammatteo, F. De Longueville, and J. Remacle. 2001. Colorimetric silver detection of DNA microarrays. Anal. Biochem. 295:1-8.

2.Ambach, E., W. Parson, H. Niederstatter, and B. Budowle. 1997. Austrian Caucasian population data for the quadruplex plus amelogenin: refined mutation rate for HumvWFA31/A. J. Forensic Sci. 42:1136-1139.

3.Anthony, R.M., T.J. Brown, and G.L. French. 2000. Rapid diagnosis of bacteremia by universal amplification of $23 \mathrm{~S}$ ribosomal DNA followed by hybridization to an oligonucleotide array. J. Clin. Microbiol. 38:781-788.

4.Becker, K., R. Roth, and G. Peters. 1998. Rapid and specific detection of toxigenic Staphylococcus aureus: use of two multiplex PCR enzyme immunoassays for amplification and hybridization of staphylococcal enterotoxin genes, exfoliative toxin genes, and toxic shock syndrome toxin 1 gene. J. Clin. Microbiol. 36:2548-2553.

5.de Jonge, B.L., T. Sidow, Y.S. Chang, H. Labischinski, B. Berger-Bachi, D.A. Gage, and A. Tomasz. 1993. Altered muropeptide composition in Staphylococcus aureus strains with an inactivated femA locus. J. Bacteriol. 175:2779-2782.

6.Duggan, D.J., M. Bittner, Y. Chen, P. Meltzer, and J.M. Trent. 1999. Expression profiling using cDNA microarrays. Nat. Genet. $21: 10-14$.

7.Ginot, F. 1997. Oligonucleotide micro-arrays for identification of unknown mutations: how far from reality? Hum. Mutat. 10:1-10.

8.Kleeman, K.T., T.L. Bannerman, and W.E. Kloos. 1993. Species distribution of coagulase-negative staphylococcal isolates at a com munity hospital and implications for selection of staphylococcal identification procedures. J. Clin. Microbiol. 31:1318-1321.

9.Maidhof, H., B. Reinicke, P. Blumel, B. Berger-Bachi, and H. Labischinski. 1991. femA, which encodes a factor essential for expression of methicillin resistance, affects glycine content of peptidoglycan in methicillin-resistant and methicillin-susceptible Staphylococcus aureus strains. J. Bacteriol. 173:3507-3513.

10. Ramsay, G. 1998. DNA chips: state-of-the art. Nat. Biotechnol. 16:40-44.

11.Ryffel, C., W. Tesch, I. Birch-Machin, P.E. Reynolds, L. Barberis-Maino, F.H. Kayser, and B. Berger-Bachi. 1990. Sequence com parison of mecA genes isolated from methicillin-resistant Staphylococcus aureus and Staphylococcus epidermidis. Gene 94:137138.

12.Stranden, A.M., K. Ehlert, H. Labischinski, and B. Berger-Bachi. 1997. Cell wall monoglycine cross-bridges and methicillin hypersusceptibility in a femAB null mutant of methicillin-resistant Staphylococcus aureus. J. Bacteriol. 179:9-16.

13.Suzuki, E., K. Hiramatsu, and T. Yokota. 1992. Survey of methicillin-resistant clinical strains of coagulase-negative staphylococci for $m e c A$ gene distribution. Antimicrob. Agents Chemother. 36:429-434.

14.Unal, S., J. Hoskins, J.E. Flokowitsch, C.Y. Wu, D.A. Preston, and P.L. Skatrud. 1992. Detection of methicillin-resistant Staphylococci by using the polymerase chain reaction. J. Clin. Microbiol. 30:1685-1691.

15. Vandenvelde, C., M. Verstraete, and D. Van Beers. 1990. Fast multiplex polymerase chain reaction on boiled clinical samples for rapid viral diagnosis. J. Virol. Methods 30:215-227.

16. Vannuffel, P., M. Heusterspreute, M. Bouyer, B. Vandercam, M. Philippe, and J.L. Gala. 1999. Molecular characterization of femA from Staphylococcus hominis and Staphylococcus saprophyticus, and femAbased discrimination of staphylococcal species. Res. Microbiol. 150:129-141.

17.Vannuffel, P., P.F. Laterre, M. Bouyer, J. Gigi, B. Vandercam, M. Reynaert, and J.L. Gala. 1998. Rapid and specific molecular identification of methicillin-resistant Staphylococcus aureus in endotracheal aspirates from mechanically ventilated patients. J. Clin. Microbiol. 36:2366-2368.

18.Zammatteo, N., L. Jeanmart, S. Hamels, S. Courtois, P. Louette, L. Hevesi, and J. Remacle. 2000. Comparison between different strategies of covalent attachment of DNA to glass surfaces to build DNA microarrays. Anal. Biochem. 280:143-150.

Received 11 June 2001; accepted 13 August 2001.

Address correspondence to:

Dr. Sandrine Hamels

Laboratoire de Biochimie Cellulaire

Facultés Notre-Dame de la Paix

Rue de Bruxelles, 61

B-5000 Namur, Belgium

e-mail: sandrine.hamels@fundp.ac.be

For reprints of this or any other article, contact Reprints@BioTechniques.com 